\title{
GESTÃo DOS RECURSOS HÍDRICOS E CONFLITO: estudo de caso da Comunidade Mãe D’Água, na bacia hidrográfica do rio Piranhas-Açu, Paraíba
}

\author{
Juliana Fernandes Moreira ${ }^{*}$, Pedro Costa Guedes Vianna², Maristela Oliveira de Andrade ${ }^{3}$, Valter Felix da \\ SILVA FiLHo ${ }^{4}$
}

${ }^{1}$ Professora Dra. da Universidade Federal da Paraíba vinculada ao Departamento de Gestão Pública. Membro fundadora do Instituto de Pesquisa e Extensão Perspectivas e Desafios de Humanização do Direito Civil Constitucional (IDCC)

${ }^{2}$ Professor Dr. da Universidade Federal da Paraíba vinculado ao Departamento de Geociências.

${ }^{3}$ Professora Titular aposentada da Universidade Federal da Paraíba vinculada ao Departamento de Ciências Sociais.

${ }^{4}$ Discente do curso de Graduação em Direito da Universidade Federal da Paraíba. Membro do grupo de pesquisa "Direito ao acesso à água em tempos de crise hídrica" junto ao Instituto de Pesquisa e Extensão Perspectivas e Desafios de Humanização do Direito Civil Constitucional (IDCC)

* Autor para correspondência:jfernandesmoreira@gmail.com

Recebido em 10 de outubro de 2017. Aceito em 19 de março de 2018. Publicado em 28 de dezembro de 2018.

REsumo - O semiárido nordestino vem sofrendo há cinco anos um período de escassez hídrica com graves repercussões na vida dos seus habitantes, nas atividades econômicas e no ambiente. Torna-se vital em uma situação como essa, uma gestão de recursos hídricos eficiente para minimizar ou contornar as situações de conflito pelo direito ao acesso à água que surgem. A presente pesquisa teve como objetivo analisar a gestão dos recursos hídricos na Bacia Hidrográfica Piranhas-Açu e um conflito por acesso à água que vem ocorrendo na Comunidade Mãe D’Água, localizada no município de Coremas-PB. Para tanto se fez uso da pesquisa bibliográfica, documental e de campo.

Palavras-chave: Recursos Hídricos, Conflito, Gestão.

Water resources management and conflict: a case study of the Mãe D’Água Community, in the Piranhas-Açu river basin, Paraíba

Aвstract - The Brazilian Northeast semi-arid has been suffering for five years a period of water scarcity with serious repercussion on the lives of its inhabitants, the economic activities and the environment. It is vital in such context an efficient water resource management to minimize or circumvent situations of conflict over the right to access water. The present research aims to analyze the management of water resources in the Piranhas-Açu Hydrographic Basin and a conflict for access to water that is occurring in Mãe D’Água Community, located in the municipality of Coremas-PB. For this purpose, the research made use of bibliographical, documentary and field research.

Keywords: Water Resources, Conflict, Management.

Gestión de los recursos hídricos y conflicto: estudio de caso de la comunidad Mãe D’Água em la cuenca hidrográfica del Piranhas-Açu, Paraíba

RESUMEN - El semiárido nordestino ha sufrido desde hace cinco años un período de escasez hídrica con graves repercusiones en la vida de sus habitantes, en las actividades económicas y en el ambiente. Es de suma importancia, en una situación como ésta, una gestión de recursos hídricos eficiente para minimizar o eludir las situaciones que surgen de conflicto por el derecho al acceso al agua. La presente investigación tuvo como objetivo analizar la gestión de los recursos hídricos en la Cuenca 
Hidrográfica Piranhas- Açu y un conflicto por el acceso al agua que ha ocurrido en la Comunidad Mãe D’Água, ubicada en el Municipio de Coremas-PB. Para ello, se utilizó una investigación bibliográfica, documental y de campo.

Palabras clave: Recursos Hídricos, Conflicto, Gestión.

\section{INTRODUÇÃO}

Elemento essencial à sobrevivência humana e motivadora de diversos conflitos em torno de sua apropriação e gestão, a água é considerada um bem ambiental, juridicamente reconhecido e que, como tal, recebe a proteção do Direito (Beviláqua 1927, Coelho 2012). Além disso, trata-se de uma substância finita e um elemento fundamental, já que propicia a vida, sendo responsável por satisfazer as nossas necessidades fisiológicas, como, por exemplo, manter o pleno funcionamento dos órgãos vitais. Para Correia (1996), a água é um suporte indispensável dos ecossistemas e um componente ambiental ao qual é atribuído cada dia mais importância. Devido a sua relevância, a discussão acerca do acesso à água, especialmente em momentos de escassez hídrica, vem ganhando espaço nos debates realizados seja pela sociedade civil, seja pelo poder público.

Ao abordar a questão da água faz-se mister distinguir dois conceitos: o da água em si e o de recursos hídricos. Segundo Lemos e Lemos (2009) a água enquanto recurso natural, no mais das vezes, é confundida com o instituto recurso hídrico. Todavia, embora não se excluam, até se completem, não são iguais. Para os autores citados, enquanto a água é um bem ambiental necessário à vida de todos os seres, é o gênero, o recurso hídrico nada mais é que "a água, a partir do momento em que passa a ser valorada economicamente (...) de forma a ser necessária para, além das necessidades fisiológicas do homem, o desenvolvimento sócio-político-econômico da sociedade (Lemos e Lemos 2009 p7).

No que se refere à gestão das águas, Lanna (1999) argumenta que esta envolve atividades voltadas apenas à regulação do uso, do controle e da proteção das águas, e à avaliação, em conformidade com a situação, coerente com os princípios doutrinários estabelecidos pela Política das Águas. Por sua vez, a noção de gestão de recursos hídricos envolve as implicações de ordem econômica, jurídica e social, sendo, portanto o conceito mais adequado para ser utilizado em uma perspectiva mais abrangente de gestão.

Em regiões acometidas por grandes períodos de escassez hídrica, como é o caso do semiárido brasileiro e, consequentemente, do semiárido paraibano e potiguar, onde se localiza a Bacia Hidrográfica Piranhas-Açu, a necessidade de uma gestão hídrica eficiente torna-se fundamental. Isto porque, entre outros problemas que surgem nesses períodos, se distinguem os conflitos relativos à apropriação e a destinação da água para seus múltiplos usos.

Entende-se por bacia hidrográfica a "área geográfica dotada de determinada inclinação em virtude da qual todas as águas se dirigem, direta ou indiretamente, a um corpo central de água.” (Pompeu 2010 p.315). O território brasileiro até 2003, era dividido em 7 regiões hidrográficas, passando, a partir da Resolução no 32, de 15 de outubro de 2003, do Conselho Nacional de Recursos Hídricos/Ministério do Meio Ambiente, a ser organizado em 12 regiões, nas quais se encontram as bacias hidrográficas. Estas se superpõem à divisão política-administrativa brasileira desconsiderando seus limites na medida em que uma única bacia pode abarcar vários estados.

Das doze regiões hidrográficas brasileiras, a Região Hidrográfica Atlântico Nordeste Oriental (que abrange parcial ou totalmente o território dos estados do Piauí, Ceará, Rio Grande do Norte, Paraíba, Pernambuco e Alagoas) compreende, dentre outras bacias, a do Rio Piranhas-Açu.

Há quem considere que os conflitos não devem ser vistos sob um aspecto negativo, mas encarados como algo normal nas relações entre os seres humanos e um "motor de mudanças" (Lederach 2012 p17). Contudo, na linguagem jurídica o conflito é entendido como sinônimo de embate, oposição, pendência, pleito, litígio (Tartuce 2008), via de regra, de conotação negativa.

Os conflitos sempre se fizeram presentes na história da humanidade "expressando-se através da luta entre os homens e o meio natural, social, familiar e político, o homem e entidades sobrenaturais e até mesmo entre 
o homem e o seu mundo íntimo" (Moreira 2008, p.42). Sampaio e Braga Neto (2007) definem o conflito como "um conjunto de propósitos, métodos ou condutas divergentes, que acabam por acarretar um choque de posições antagônicas, em um momento de divergências entre as pessoas" (p. 35). Simmel (1983), por sua vez, compreende o conflito como um processo de associação, no qual sentimentos como o ódio, a inveja, a necessidade e o desejo são elencados como fatores inerentes a ele. Assim sendo, o conflito tem por fulcro solucionar posicionamentos antagônicos, trazendo a ordem, a unidade, mesmo que para tanto seja necessário a desconstrução de uma das partes da relação, o que leva a assertiva que não implicará em uma conciliação, tampouco nos leva a uma conotação negativa (Theodoro 2005 p54). No caso de áreas sujeitas à secas rigorosas, a eclosão e o acirramento de conflitos exige uma gestão dos recursos hídricos visando minimizá-los ou solucioná-los.

No que se refere a conflitos hídricos, há vários trabalhos já publicados, todavia, não referente ao conflito na Comunidade Mãe D’Água. Pinheiro et al (2011), Mauro (2014), Santos et al (2011), dentre outros, nos trazem o estudo realizado em conflitos distintos, mas que têm por epicentro a água.

O propósito do presente trabalho é entender a relação existente entre gestão hídrica e conflito pelo direito de acesso à água em regiões submetidas a forte escassez hídrica a partir do estudo de caso da comunidade Mãe D’Água, situada na Bacia Hidrográfica Piranhas-Açu, no município de Coremas-PB, uma vez que não houve nenhum outro conflito semelhante ao que nela vem ocorrendo na área da bacia hidrográfica na qual ela se encontra.

\section{Material e MÉtodos}

Do ponto de vista metodológico o trabalho pautou-se na pesquisa bibliográfica e documental e no estudo de caso. A pesquisa bibliográfica parte do levantamento de referências teóricas já analisadas e publicadas, sendo indispensável a qualquer pesquisador uma vez que ela permite conhecer o que já se estudou ou se produziu sobre o assunto (Fonseca 2002). Para a realização deste artigo foi realizada pesquisa de obras, artigos e teses que tratam dos temas água, recursos hídricos e conflito, a exemplo da obra "Direito de Águas no Brasil", de Cid Tomanik Pompeu (2010), do artigo Governança das águas no Brasil: conflitos pela apropriação da água e a busca da integração como consenso de Valéria Nagy de O. Campos e Ana Paula Fracalanza (2010), da Tese de Alcides Leite de Amorim, que aborda os mecanismos de resolução de conflitos em bacias hidrográficas compartilhadas (2016) etc.

A pesquisa documental utilizou fontes diversificadas sem tratamento analítico, tais como Constituições Federais, Leis e Decretos, relatórios e documentos oficiais.

O estudo de caso foi realizado na Comunidade Mãe D’Água, localizada no município de Coremas, no estado da Paraíba, mais precisamente às margens da barragem que leva o mesmo nome. O motivo que levou a escolha do conflito existente nesta Comunidade deu-se em decorrência da especificidade dele, uma vez que a população envolvida possuía água em abundância, mesmo a região estando acometida por uma grave crise hídrica. Diante disso, optou-se por realizar um relato da experiência caracterizando o conflito vivenciado.

Para uma apreensão mais objetiva da realidade foram realizadas entrevistas após a leitura e devido preenchimento do Termo de Livre Consentimento, permitindo a utilização da imagem, inclusive. Dentre os atores sociais envolvidos no conflito, que foram entrevistados, podemos citar a líder comunitária local e outros moradores da comunidade, representante do Comitê da Bacia Piancó-Piranhas-Açu e Coordenador de Projetos da Agência de Desenvolvimento Sustentável do Seridó (ADESE), professor da Universidade Federal de Campina Grande (UFCG), que participou de uma das reuniões do Comitê da Bacia na qual fizemo-nos presente, e a sócia e responsável técnica da Projecte-Engenharia, Arquitetura, Construção e Consultoria Ltda., empresa contratada pela Agência Nacional das Águas (ANA) para prestação de serviços técnicos de apoio à gestão de recursos hídricos na Bacia Hidrográfica do Piranhas-Açu. Durante os trabalhos de campo foi possível efetuar registros fotográficos e de vídeo. 
Com base nessa metodologia, os resultados foram estruturados em três segmentos: o primeiro aborda a evolução da legislação de gestão dos recursos hídricos no Brasil, o segundo caracteriza a bacia hidrográfica do Rio Piranhas-Açu e ressalta a importância do sistema Curema-Mãe D’Água para o abastecimento de municípios do estado da Paraíba e do Rio Grande do Norte, e, o terceiro descreve o conflito pelo uso da água que eclodiu na Comunidade Mãe D’Água e a forma de intervenção dos gestores dos recursos hídricos buscando apreender os fatores responsáveis pelo conflito e identificar possíveis indicações de ação para evitar a repetição dos fatos.

\section{Caracterização da bacia hidrográfica do rio Piranhas-Açu}

A bacia hidrográfica alvo desta pesquisa estende-se desde a nascente do rio Piancó, na serra do Piancó, estado da Paraíba, até a desembocadura do rio Açu, no município de Macau, localizado no estado do Rio Grande do Norte, percorrendo $405 \mathrm{~km}$ (Rio et al 2016). Ela abrange total ou parcialmente 147 municípios, dos quais 47 pertencem ao RN e 100 à PB. A população estimada para 2014 era de 1.617.144 habitantes segundo o IBGE (Censo 2010). O rio principal, o Piranhas, sofre alteração em seu nome no Rio Grande do Norte, mais precisamente ao sair do maior reservatório de água da bacia, o Açude Engenheiro Armando Ribeiro Gonçalves, momento em que passa a se chamar Rio Açu.

A bacia hidrográfica supracitada é federal, uma vez que o curso do seu principal rio, o Piranhas-Açu, percorre dois estados membros, nascendo na Paraíba, no município de Bonito de Santa Fé, e desaguando no município de Macau, localizado ao norte do Rio Grande do Norte. É ela, inclusive, a mais importante bacia da região semiárida desses dois estados, onde se encontram os maiores reservatórios da região, Armando Ribeiro Gonçalves, no RN, e o sistema Curema-Mãe D’Água, na PB, estratégicos para o desenvolvimento socioeconômico da região.

Toda área da bacia está inserida na região semiárida do Nordeste brasileiro, considerada a região semiárida mais populosa do mundo. Um conjunto de fatores naturais, sociais e econômicos desafia a gestão das águas da bacia, como apontado no Plano de Recursos Hídricos da bacia:

Situada na região Nordeste do país, essa região se caracteriza em termos de recursos hídricos por apresentar uma conjugação negativa de fatores que desafiam a gestão: elevada demanda de água (principalmente para abastecimento humano e irrigação) e alta carga poluidora de esgotos domésticos associadas à baixa disponibilidade hídrica, característica do clima semiárido, em que muitos rios são intermitentes (ANA 2014 p6).

A região Nordeste, especialmente a área do Polígono das Secas ${ }^{1}$, tem sua história ambiental, social e econômica relacionada com a ocorrência periódica do fenômeno das estiagens prolongadas. Algumas destas, como a seca de 1844-46, embora devastadora, não sensibilizou o governo imperial no sentido de tomar providências eficazes para prevenir os efeitos da falta de água em futuros períodos de estiagem. Assim, trinta anos depois, em 1877, outro período de seca, que durou três anos, assumiu um caráter dramático, sendo considerada uma das piores já registradas no Brasil a partir da instauração da Colônia. Estima-se que provocou a morte de mais de 2 milhões de nordestinos. Só então o Estado brasileiro passa de forma mais objetiva a se preocupar com a gestão das águas no país.

A política de gestão instituída voltou-se à implementação do combate à seca, à intervenção emergencial para socorrer as vítimas das secas, ao armazenamento de água em barragens e açudes para tornar a região mais resistente às secas e à irrigação.

1 O Polígono das Secas foi criado em 7 de janeiro de 1936, pela Lei 175/36 e compreendia a área constituída pelos estados nordestinos sujeitos às secas. Ele abrangia uma área de $947.150 \mathrm{~km}^{2}$, que envolvia os estados do Piauí, Ceará, Rio Grande do Norte, Paraíba, Pernambuco, Alagoas, Sergipe, Bahia e norte de Minas Gerais. As mais recentes delimitações do semiárido ampliaram a área do Polígono uma vez que incluíram novos municípios antes excluídos. 
Embora a concepção que deu origem à chamada "solução hidráulica" envolvesse não apenas o armazenamento da água, como também a sua utilização para fins produtivos (irrigação e piscicultura) e a preservação do revestimento florestal, a sua implementação, contudo, priorizou o aspecto do armazenamento de água através da construção de grandes açudes e represas. Esse tratamento do problema vai ser reforçado após a criação da IOCS em 1909 e pelas suas posteriores transformações em IFOCS (1919) e DNOCS (1945). Com efeito, sob o comando desses órgãos teve lugar um avanço significativo na infra-estrutura de armazenagem de água na região (Moreira e Targino 2016).

Esta política originou a construção de grandes barragens e de açudes menores, porém foi orientada nitidamente para o fortalecimento das oligarquias rurais uma vez que os açudes foram construídos em grande parte nas propriedades privadas, reforçando "o poder dos coronéis sobre o conjunto da população, pois eles passavam a deter não só o controle das terras, mas também o controle das águas, elementos fundamentais à sobrevivência humana" (Moreira e Targino2016 p75).

Três desses açudes foram construídos pelo DNOCS na Bacia Hidrográfica Piranhas-Açu: o de Curema e o de Mãe D’água (que foram interligados) no trecho da bacia localizado no estado da Paraíba, na primeira metade do século XX, ainda no âmbito da intervenção estatal denominada de política de solução hidráulica para a seca no semiárido nordestino, e o açude Engenheiro Armando Ribeiro Gonçalves construído no trecho da bacia localizado no Rio Grande do Norte, durante a fase de intervenção estatal pautada numa visão desenvolvimentista que, entre outros, visava a construção de açudes atrelados à criação de projetos de irrigação com foco na produção de frutas para o mercado externo e para unidades de beneficiamento.

Os açudes Curema e Mãe D’Água, situados no município de Coremas-PB e o açude Engenheiro Armando Ribeiro Gonçalves, localizado no município de Itajá-RN, são responsáveis pela perenização do rio que dá nome a Bacia Hidrográfica Piranhas-Açu, além de serem essenciais aos perímetros irrigados existentes da região, dentre os quais: o Perímetro Irrigado das Várzeas de Souza, na Paraíba, e o Perímetro Irrigado do Baixo Açu, no Rio Grande do Norte, responsáveis pela produção de coco, banana, melão, dentre outros.

Vale ressaltar que os dois primeiros formam o sistema Curema-Mãe D’Água, onde é possível o encontro de suas águas, a depender de seus volumes, possuindo capacidade de armazenamento de aproximadamente 1,350 bilhões de $\mathrm{m}^{3}$, enquanto o último possui capacidade total de aproximadamente 2,4 bilhões de $\mathrm{m}^{3}$ (AESA 2017).

Ademais, o sistema Curema-Mãe D’Água, por meio do reservatório Mãe D’Água, é responsável por levar água à Comunidade Mãe D’Água, localizada no município de Coremas, e ao Perímetro Irrigado das Várzeas de Sousa (PIVAS), nos municípios de Sousa-PB e Aparecida-PB, através de um canal chamado de Canal da Redenção (Figura 1). 
Figura 1. Início do Canal da Redenção às margens da Barragem Mãe D’Água

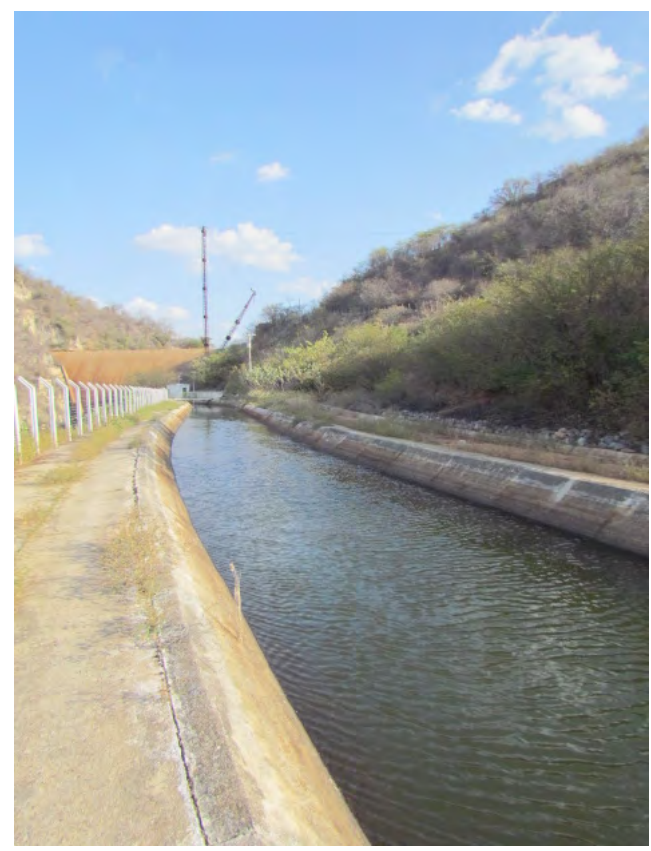

Fonte: Arquivo Pessoal de Juliana Fernandes Moreira, 2017

O canal da Redenção, com extensão de $37 \mathrm{~km}$, foi construído com recurso estadual, tendo por objetivo possibilitar a irrigação no PIVAS, bem como servir aos proprietários de terras situadas às suas margens (Lima 2006). Já o açude Curema é responsável pelo abastecimento do próprio município de Coremas-PB, que conta com uma população estimada de aproximadamente 15.400 habitantes em 2014 segundo o IBGE e outros 24 municípios localizados na Paraíba e no Rio Grande do Norte.

Um quarto reservatório, o Açude Oiticica, com capacidade total de armazenamento de 592 milhões de $\mathrm{m}^{3}$, localizado nos municípios de Jucurutu, São Fernando e Jardim de Piranhas, no Rio Grande do Norte, está sendo construído, com previsão de conclusão para dezembro de 2018, segundo dados fornecidos pelo representante do Comitê da Bacia Hidrográfica Piancó-Piranhas-Açu.

Dentre as principais atividades econômicas desenvolvidas na região da Bacia do Rio Piranhas-Açu destacamse a exploração de gás, petróleo e sal, além de uma rica produção têxtil e de cerâmicas, bem como aquicultura e atividades agrícolas irrigadas, sendo a última estimulada na década de 1970 pelo governo federal no bojo da expansão do capital sobre a agricultura.

No que diz respeito à irrigação, segundo o plano da bacia hidrográfica Piranhas-Açu, é ela responsável pelo consumo de $65,7 \%$ da demanda total por água da região. Todavia, 56\% dos irrigantes ainda utilizam o método de irrigação por aspersão, responsável por consumir um elevado índice de água, o que gera um desperdício significativo desse recurso hídrico. Dentre os métodos de irrigação é preferível que se faça uso daqueles mais eficientes, ou, porque não dizer, sustentáveis, como, por exemplo, microaspersão e gotejamento que só são utilizados em 9\% da área da bacia.

Desde 2012, o semiárido vem sofrendo com mais uma estiagem. Esse longo período de seca promoveu a diminuição do volume das águas dos açudes, gerando uma maior preocupação com relação à gestão dos recursos hídricos. Segundo a AESA (2017), com capacidade total de $591.646 .222 \mathrm{~m}^{3}$, o Açude Curema, em setembro de 2016, encontrava-se com apenas 3,1\% de sua capacidade total (equivalente à $18.412 .061 \mathrm{~m}^{3}$ de água). Em outras palavras o açude entrou em colapso gerando sérios problemas para os 23 municípios que ele abastece. Segundo dados disponibilizados pela AESA, em seu site www.aesa.pb.gov.br, em 17 de abril de 2017, o reservatório Curema encontrava-se com 7,5\% de sua capacidade total, o que demonstra uma melhora do volume de água armazenado, mas que está longe do volume necessário ao atendimento da população que dele depende. 
No que diz respeito aos outros dois principais reservatórios localizados na Bacia Hidrográfica do Rio PiranhasAçu, ou seja, o Mãe-D’Água e o Armando Ribeiro Gonçalves, assim como o Curema, eles se encontravam com baixíssimo volume de água em 2016. Segundo dados obtidos junto ao site da AESA e do DNOCS, respectivamente, no mês de abril o volume registrado foi de $30.870 .000 \mathrm{~m}^{3}$ (5,4\%), para o Mãe D’Água, e de $457.425 .600 \mathrm{~m}^{3}$ (19\%) para o Armando Ribeiro Gonçalves.

Esse quadro é responsável pela eclosão de conflitos latentes que exigem a intervenção do Estado, a participação das comunidades e de movimentos sociais.

\section{RESUltados E Discussão}

\section{Evolução da legislação de gestão dos recursos hídricos no Brasil}

As primeiras constituições brasileiras, apesar de não tratarem especificamente da temática das águas, trouxeram em seu texto constitucional a quem pertencia o domínio destas. Exemplo disso, é a Constituição do Império de 1824, que estabelecia que todos os rios pertenciam à Coroa Portuguesa (Granziera 2014). A Magna Carta de 1934, já no século XX, estabelecia, expressamente, em seu art. 20, inciso II, que eram do domínio da União: “os lagos e quaisquer correntes em terrenos do seu domínio ou que banhem mais de um Estado, sirvam de limites com outros países ou se estendam a território estrangeiro.” (Brasil 1934).

Em 1934 foi promulgado o Decreto no 24.643, mais conhecido como Código de Águas, tido como marco legal inicial da legislação de recursos hídricos no Brasil. "O citado Código refletiu, na oportunidade, uma mudança nas diretrizes do país, que migrava suas atenções do setor agrário para o urbano industrial e precisava viabilizar a geração de hidrelétrica" (Leite 2015 p.1). Esta mudança esteve relacionada à quebra da bolsa de valores de New York, em 1929, que acarretou a derrocada da produção cafeeira do Centro-Sul do país levando os cafeicultores a voltar-se para o setor industrial que demanda energia elétrica, motivando, assim, o crescimento significativo do setor energético (Cano 2015). Um dos mecanismos trazidos por esse Código, em seu artigo 43, foi a necessidade de autorização, perante o Poder Público, para utilização da água independentemente do setor ao qual seria destinada, a não ser que o volume de captação fosse considerado insignificante (Brasil 1934). "A regulamentação do Código de Águas permitiu remover obstáculos legais que restringiam o aproveitamento de seu potencial hidrelétrico, atendendo aos interesses emergentes do setor urbano industrial" (Leite 2015 p1).

Alguns dispositivos do Código das Águas se mostram, ainda hoje, bastante atuais. Pode-se destacar o princípio poluidor-pagador, no parágrafo $2^{\circ}$ do artigo 36, segundo o qual "o uso comum das águas pode ser gratuito ou retribuído", apesar de o artigo 34 ressalvar que "é assegurado o uso gratuito de qualquer corrente ou nascente para as primeiras necessidades da vida...”.

Com a instituição da Política Nacional de Saneamento e a criação do Conselho Nacional de Saneamento (Lei 5.318/67) em 1967, foi incorporado o conceito de planejamento integrado, uma vez que ela prevê a integração entre as políticas de Saúde e Saneamento.

A Constituição Federal promulgada em 1988 trouxe, segundo Leite (2015):

aperfeiçoamentos importantes aos dispositivos de gestão dos recursos hídricos originários do Código de Águas, mas mostrou-se muito centralizadora, estabelecendo que "compete privativamente à União legislar sobre as águas e energia (...), regime dos portos, navegação lacustre, fluvial, marítima” porém considera que lei complementar autorize os Estados a legislar sobre questões específicas da matéria acima (Parágrafo único do art. 22 da CF/88). Nesta constituição ficou definido a propriedade da água bem como estabeleceu no inciso XIX do artigo 21 
que "compete à União instituir o sistema nacional de gerenciamento de recursos hídricos e definir critérios de outorga de direitos de seu uso" (p.3)

Assim, foi a partir da promulgação da Constituição Federal de 1988, que a União e os estados-membros deram início à criação de seus sistemas de gerenciamento de recursos hídricos, de modo que foi possível enxergar o surgimento de diversas instituições locais e federais responsáveis pela sua gestão, como a Agência Executiva de Gestão das Águas (AESA), Instituo de gestão das águas (IGARN), ANA, dentre outros. Foi também esta CF, em seu artigo 20, inciso III, que estabeleceu como bens da união:

os lagos, rios e quaisquer correntes de água em terrenos de seu domínio, ou que banhem mais de um Estado, sirvam de limites com outros países, ou se estendam a território estrangeiro ou dele provenham, bem como os terrenos marginais e as praias fluviais. (Brasil 1988).

É necessária uma interpretação mais ampla ao realizar a análise da norma jurídica supracitada. Na verdade, ao declarar que tais objetos discutidos no inciso pertencem à própria União, não se quer chamar atenção para a ideia de propriedade que o órgão possui em relação ao bem, mas, sim, para a responsabilidade da instituição pela administração do mesmo. Nesse sentido, como bem afirma Sérgio Leite (2015) a Constituição Federal de 1988 (CF/88) ainda foi muito centralizadora.

Desse modo, historicamente, até o advento da Lei 9.433/97 o modo como se deu a gestão das águas no território brasileiro foi centralizado e fragmentado, já que cada setor interessado pelo seu uso (energia elétrica, agricultura, entre outros) realizava seu próprio planejamento de utilização dos recursos hídricos. Além disso, todo gerenciamento estava concentrado nas mãos do governo federal, de modo que não havia participação na gestão, do poder público municipal, da sociedade civil e nem mesmo dos principais interessados, ou seja, dos próprios usuários (Campos e Fracalanza 2011).

Só em 1997, com a implementação da Lei 9.433/97 da Política Nacional de Recursos Hídricos (PNRH) e o Sistema Nacional de Recursos Hídricos (SINGREH) é que a gestão dos recursos hídricos no Brasil se descentralizou. Ela se inspira no modelo francês de gestão desses recursos, caracterizado por ter a bacia hidrográfica como unidade de gestão e a descentralização como elemento fundante. Seus principais objetivos são: assegurar disponibilidade de água com qualidade para gerações atuais e futuras, a utilização racional e integrada de água visando o desenvolvimento sustentável e a prevenção contra eventos críticos. Os conceitos que fundamentam esta Lei são os seguintes: a água é um recurso natural finito, sua utilização prioritária é para consumo humano e animal, a ênfase é dada ao aproveitamento múltiplo, além do que já foi mencionado, a adoção da bacia hidrográfica como unidade de planejamento.

No que diz respeito às diretrizes, o PNRH determina:

associação dos aspectos quantitativos e qualitativos da água, adequação das ações às diversidades regionais, integração da gestão dos recursos hídricos com a gestão ambiental, integração da gestão dos recursos hídricos com a gestão costeira e estuarina, articulação com planejamentos setoriais, regionais, estaduais e nacional, articulação com a gestão do solo (Leite 2015 p2).

Para cumprir os objetivos da PNRH, foi definida uma série de instrumentos quais sejam: planos de recursos hídricos (planos diretores por bacias, compatibilizados com os estados e unificados para o país), outorga de direito de uso da água, cobrança pelo uso da água, sistema de informações sobre recursos hídricos, compensação a municípios, enquadramento dos corpos d'água (Leite 2015).

A Lei 9.433/97 também foi responsável por instituir o Sistema Nacional de Gerenciamento dos Recursos Hídricos (SNGRH), sendo esse sistema um conjunto de entidades responsáveis, segundo o artigo 32, por: 
coordenar a gestão integrada das águas, arbitrar administrativamente os conflitos relacionados com os recursos hídricos, implementar a Política Nacional de Recursos Hídricos, planejar, regular e controlar o uso, a preservação e a recuperação dos recursos hídricos, promover a cobrança pelo uso de recursos hídricos. (Brasil 1997).

Dentre os órgãos integrantes do SNGRH, destacam-se a Agência Nacional de Águas (ANA), os Comitês de Bacia Hidrográfica e as Agências Estaduais de Água. A ANA foi instituída pela lei 9.984/2000 como uma autarquia sob regime especial vinculada ao Ministério do Meio Ambiente, sendo a entidade federal responsável pela implementação da Política Nacional de Recursos Hídricos (Brasil 2000). Por sua vez, a lei 9.433/97 determinou que os Comitês de Bacia Hidrográfica teriam como área de atuação a própria bacia hidrográfica, destacandose entre suas competências a aprovação do Plano de Recursos Hídricos da Bacia, além de acompanhar sua execução. Segundo o artigo $6^{\circ}$ da lei em epígrafe, “Os Planos de Recursos Hídricos são planos diretores que visam a fundamentar e orientar a implementação da Política Nacional de Recursos Hídricos e o gerenciamento dos recursos hídricos" (Brasil 1997). Vale ressaltar que dentre os representantes dos Comitês encontram-se os usuários das águas de sua região de atuação, bem como entidades civis relacionadas com recursos hídricos com atuação na bacia hidrográfica (Brasil 1997). Por último, esta mesma lei estabelece as Agências de Água que "exercerão a função de secretaria executiva do respectivo ou respectivos Comitês de Bacia Hidrográfica” (Brasil 1997), tendo dentre suas responsabilidades a elaboração do Plano de Recursos Hídricos, um dos instrumentos estabelecidos pela PNRH, para que seja apreciado pelo respectivo Comitê (Brasil 1997).

Há de se reconhecer que a Lei $n^{\circ} 9.433 / 97$, citada, representou um avanço significativo no planejamento e gerenciamento dos recursos hídricos no Brasil, com a participação da sociedade civil organizada, através do Comitê de Bacia, a observância das diferenças regionais e, sobretudo a convivência harmônica dos diversos organismos intervenientes na gestão das águas. Em termos técnicos, políticos e institucionais os desafios apresentados nesta primeira experiência de gestão integrada de bacia concentraram-se na interface entre setores usuários e gestores, bem como em buscar harmonizar os interesses entre os gestores federais e estaduais (Leite 2015 p3).

Com relação à Bacia Hidrográfica do Rio Piranhas-Açu, é importante destacar que sua gestão ocorre de forma compartilhada entre a União, a Paraíba e o Rio Grande do Norte, sendo a primeira representada pela ANA, o segundo pela SERHMACT (Secretaria de Estado dos Recursos Hídricos, do Meio Ambiente e da Ciência e Tecnologia do estado da Paraíba) e AESA e o terceiro pela SEMARH (Secretaria de Estado do Meio Ambiente e dos Recursos Hídricos e Minerais) e pelo IGARN (Amorim 2016).

Com sede no município de Caicó-RN, o Comitê da Bacia Hidrográfica do Rio Piranhas-Açu foi criado por meio do Decreto Presidencial s/n ${ }^{\circ}$, de 29 de novembro de 2006, tendo sua nomenclatura editada em outubro de 2016 para Comitê da Bacia Hidrográfica do Rio Piancó-Piranhas-Açu (CBHPPA), uma vez que os representantes do Comitê ressaltaram a importância do rio Piancó como o principal afluente do rio Piranhas. Posteriormente, entre os anos de 2012 e 2014 foi elaborado o Plano de Recursos Hídricos da bacia visando "compatibilizar a disponibilidade hídrica em termos qualitativos e quantitativos com as demandas de água.” (ANA 2014). Esse plano vem sendo colocado em prática, tendo, inclusive, sido apresentado à comunidade da bacia, através de reuniões com representantes da ANA, AESA, IGARN, e demais atores sociais envolvidos.

\section{Gestão dos recursos hidricos e conflito: o caso da Comunidade Mãe D'Água}

Conflitos que têm por epicentro a água vêm ocorrendo no Brasil, e sendo registradas por meio da publicação de artigos científicos. Dentre os conflitos hídricos já ocorridos podemos citar o dos rios Pacoti e Acarape, na década de 1920, o do sistema Orós-Lima Campos, na década de 1990, ambos no estado do Ceará (Pinheiro et al 
2011), o da Barragem Oiticica, no Rio Grande do Norte, o do açude Epitácio Pessoa, na Paraíba (Brito 2008). Vale ressaltar que esses conflitos podem se dar em decorrência de construção de obra hídrica, o que irá envolver outros aspectos, dentre eles outros direitos sociais além do direito ao acesso à água, da limitação que venha a sofrer o direito ao acesso à água, fruto de uma gestão hídrica ineficaz e/ou escassez hídrica, dentre outros fatores. $\mathrm{Na}$ Comunidade Mãe D’Água, atualmente, está ocorrendo um conflito em torno do direito ao acesso à água, o qual passamos a tratar.

A Comunidade Mãe D’Água, localizada próxima à barragem que leva o mesmo nome, em Coremas-PB, é uma das três comunidades remanescente de quilombos (CRQ’s) do município, com certificação pela Fundação Cultural Palmares. As comunidades quilombolas são uma das categorias das "Comunidades Tradicionais", definidas pelo Decreto Federal de ${ }^{\circ}$ 6.040/07, em seu art. $3^{\circ}$, inciso I, como:

[...] grupos culturalmente diferenciados e que se reconhecem como tais, que possuem formas próprias de organização social, que ocupam e usam territórios e recursos naturais como condição para sua reprodução cultural, social, religiosa, ancestral e econômica, utilizando conhecimentos, inovações e práticas gerados e transmitidos pela tradição do qual também fazem parte os ribeirinhos, quebradeiras de coco, pescadores. (Decreto n ${ }^{\circ}$ 6.040/2007).

Os quilombolas são descendentes de africanos que foram escravizados e que mantêm suas próprias tradições culturais ao longo dos séculos. Uma das principais funções da Fundação Cultural Palmares é registrar formalmente tais comunidades e desenvolver ações de assessoria jurídica, programas e políticas públicas para que estas possam ter acesso à cidadania. (FCP 2017).

Muitas são as dificuldades vividas por esse grupo socialmente vulnerável, para além da exclusão social ao qual está submetido. Trata-se de uma população pobre que vivencia o estado de insegurança alimentar e é submetida a trabalho sazonal, "responsável pela migração de jovens e adultos para outras cidades e regiões do país em busca de condições de trabalho". (Secretaria de Estado da Mulher e da Diversidade Humana 2011 p14).

Segundo o Relatório do I Seminário Estadual de Políticas Públicas para Comunidades Quilombolas do Estado da Paraíba, outras dificuldades básicas são por elas enfrentadas:

A infra-estrutura básica segue a mesma lógica e a carência aparece nas precárias vias de acesso às comunidades, na insuficiência ou falta de abastecimento de água, na falta de reservatórios de água, como cisternas, poços e açudes etc. (Secretaria de Estado da Mulher e da Diversidade Humana 2011 p16).

Diferentemente do exposto acima, apesar de ser uma comunidade remanescente de quilombo, Mãe D’Água possui um grande reservatório de água (o próprio açude), que, até o ano de 2016 abastecia diretamente a população local através de tubulações específicas, que são conhecidas na região como barriletes. Além disso, a maioria das casas da comunidade possui cisterna de placa. A presença destas cisternas deve-se ao incentivo do Governo Federal a partir dos anos 2000, por meio do Programa 1 Milhão de Cisternas (P1MC)difundido pela Articulação do Semiárido Brasileiro (ASA-BRASIL) com o objetivo de construir cisternas no semiárido brasileiro para amenizar os impactos causados pela seca e atender a uma necessidade básica da população que vive no campo, que é o acesso à água potável de qualidade e perto de casa. Em 2007, outro Programa foi disseminado no semiárido pela ASA, denominado Uma Terra e Duas Águas ou P1+2. Este programa tinha como objetivo aumentar a possibilidade de armazenamento de água pelas famílias beneficiadas, satisfazendo as necessidades de plantio e de criação de animais (ASA 2017).

Segundo a informante, agente comunitária de saúde há 14 anos e líder da Comunidade Mãe D’Água, 192 famílias (aproximadamente 600 moradores) compõem a população residente na Comunidade. Dentre as principais atividades econômicas nela desenvolvidas cita a agricultura irrigada (cerca de 7 hectares) e a piscicultura (em torno 
de 83 viveiros para cultivo de peixes), atividades que, notoriamente, exigem uma alta demanda por água. Portanto, diferentemente de outras CRQ’s, a Comunidade Mãe D’Água não sofria pela falta de água, uma vez que era abastecida por meio de tubulações, as quais recebem o nome de barriletes, com água proveniente diretamente do reservatório Mãe D’Água, sem controle na quantidade que era liberada. Trata-se, de fato, de um contrassenso, se levarmos em consideração o longo de período de estiagem pelo qual a região vinha sofrendo, levando, inclusive, ao colapso do reservatório Curema e a redução significativa da quantidade de água armazenada no Mãe D’Água.

Segundo a AESA, em dezembro de 2015, três anos depois do início do atual período seco, o reservatório Mãe D’Água encontrava-se com apenas $13,5 \%$ de sua capacidade total (equivalente a $76.822 .539 \mathrm{~m}^{3}$ ), o que implica em uma quantidade insuficiente para manter os municípios que dele dependem abastecidos. Diante disso, no dia 11 de dezembro do mesmo ano, o Comitê da Bacia Hidrográfica do Rio Piancó-Piranhas-Açu (CBH-PPA), a Agência Nacional de Águas (ANA) e a Agência Executiva de Gestão das Águas da Paraíba (AESA) reuniram os moradores da Comunidade para repassar as decisões que foram tomadas pelo Comitê em uma reunião realizada no dia 20 de novembro de 2015 no município de Pombal-PB.

Dentre as informações que foram passadas para os moradores, destacam-se: a) a que previa a retirada das tubulações que abastecem a comunidade diretamente com a água proveniente do açude pela Companhia de Água e Esgotos da Paraíba (CAGEPA) quando se encontrasse uma alternativa para o abastecimento da comunidade, e, b) a provável suspensão da atividade de piscicultura no ano de 2016. Diante dessas informações que foram passadas para a comunidade, por meio do CBH PPPA, ela reagiu e em 11 de novembro de 2015 deu início a uma mobilização voltada para a garantia do seu abastecimento d'água.

Em 2016, no dia 11 de abril foi publicado no Diário Oficial da União a Resolução de no 407/2016 da ANA, proibindo captações de água no Açude Mãe D’Água, seja de forma direta ou por meio dos barriletes, para fins de atividade de irrigação e aquicultura, cumprindo-se o que tinha sido repassado pelo CBH-PPA à Comunidade. Além disso, estabeleceu-se que a vazão média mensal do reservatório para o Canal da Redenção estaria limitada a 4001/s. Tais medidas adotadas pelos gestores hídricos estão relacionadas às determinações da Política Nacional de Recursos Hídricos que, no seu Artigo $1^{\circ}$, determina que em situações de escassez, o uso prioritário dos recursos hídricos é o consumo humano e a dessedentação de animais. (Brasil 1997).

Segundo representante do Comitê da Bacia do Rio Piancó-Piranhas-Açu e Coordenador de Projetos da Agência de Desenvolvimento Sustentável do Seridó (ADESE), mesmo com tais regulamentações expedidas pela ANA, a Comunidade Mãe D’Água continuou fazendo uso da água proveniente do açude, por meio das tubulações e a exercer as atividades então proibidas. Isso teria levado funcionários da ANA no dia 15 de julho de 2016, a retirar os barriletes, impossibilitando assim o acesso da população à água do açude.

A líder comunitária relatou que a partir dessa ação da ANA, a população de Mãe D’Água teria ficado cerca de três meses sem acesso à água, tempo levado pela CAGEPA para a criação de um novo sistema de abastecimento.

[...] a gente foi surpreendido com esse mando da Agência Nacional de Águas para que retirasse os nossos barriletes. O que era um barrilete? Barriletes eram tubulações que a gente tinha, que a comunidade tinha, que supria toda a comunidade lá, pra encher os viveiros de pesca, e eles vieram com uma ordem. A gente foi roubado. No dia 15 de julho de 2016 eles vieram e tiraram os nossos barriletes e deixaram a comunidade sem água. Do nada, sem água, de nada. E a gente passou três meses lutando contra isso, né!? Várias foram as tentativas, ai entrou outros órgãos... Entrou a CAGEPA, que a CAGEPA fez um sistema provisório, que a gente acha que esse sistema seja provisório, e que, um dia, quando o açude, se Deus quiser voltar a encher, a gente tenha os nossos barriletes de volta. (entrevista com M.A.S. 2017).

A crise hídrica que culminou com o colapso dos açudes Curema-Mãe D'Água e a ação da ANA no cumprimento do que determina a da Política Nacional de Recursos Hídricos nesses casos, trouxe graves consequências para a 
comunidade quilombola Mãe D’Água. A sua economia, tradicionalmente baseada na piscicultura foi completamente desarticulada e a população passou a viver, a partir de então, da assistência do Governo Federal por meio do programa Bolsa Família e da aposentadoria, como nos relatou Maria Aparecida.

O representante do Comitê de Bacia, E.G., argumenta, em defesa da ANA, que a Comunidade Mãe D’Água com cerca de 600 pessoas, gastava mais água do que o município de Campina Grande-PB, o segundo maior município do estado da Paraíba, no que diz respeito ao número de habitantes. Segundo E.G., enquanto a comunidade Mãe D’Água consumia cerca de 7501/s, Campina Grande consome cerca de 6001/s. "É incoerente que 600 pessoas, em período de crise, consumam uma quantidade superior de água do que mais de 300 mil indivíduos. É necessário que a comunidade se adapte à situação, pois tal medida adotada resulta de uma boa gestão de recursos hídricos" (entrevista com EG).

Segundo P.A.O., professor da Universidade Federal de Campina Grande (UFCG), além do dado acima informado, é necessário entender que há mais de 40 anos que as casas da comunidade não possuem caixa d'água, sendo esta retirada diretamente do açude pela tubulação e utilizada sem nenhum tipo de restrição. Assim sendo, a água consumida, em sua maior parte, não está destinada ao abastecimento humano, mas à criação de peixes.

A ação realizada por parte da ANA foi discutida entre os órgãos gestores e a sociedade civil desde o ano de 2015, inclusive, aprovada em reunião com a presença do Ministério Público. Ainda, segundo T.G.A., sócia e responsável técnica da Projecte-Engenharia, Arquitetura, Construção e Consultoria Ltda.,- empresa contratada pela ANA para prestação de serviços técnicos de apoio à gestão de recursos hídricos na Bacia Hidrográfica do Piranhas-Açu -, a comunidade teria ficado sem acesso à água durante o período de implementação do novo sistema de abastecimento da mesma, devido a recusa por parte dos próprios moradores em aceitar a água levada por caminhões pipa.

Posteriormente, em setembro de 2016, o reservatório Curema, alcançou seu volume morto, segundo dados da AESA (2016), ficando apenas com 3,1\% de sua capacidade total, equivalente a $18.412 .061 \mathrm{~m}^{3}$ de sua capacidade total (Figura 2), impossibilitando a perenização do rio Piancó e a chegada de água aos 24 municípios por ele abastecidos.

Figura 2. Situação hídrica do Açude Curema em novembro de 2016 - Coremas-PB.

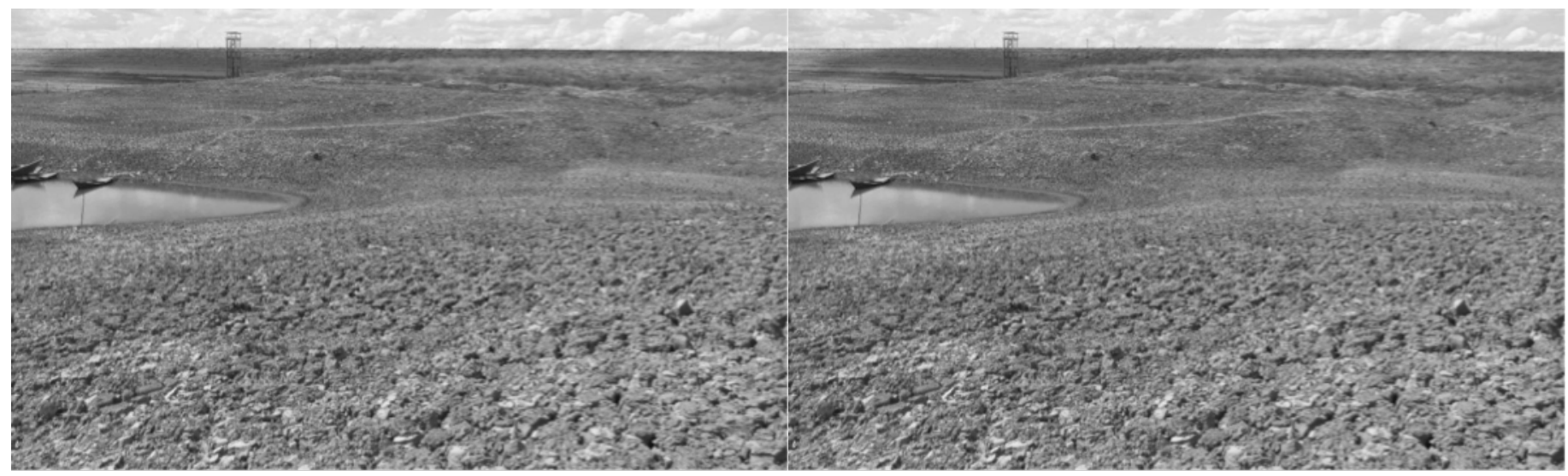

Fonte: Arquivo Pessoal de Juliana Fernandes Moreira, 2016

Diante disso, a solução encontrada pelos órgãos gestores foi a abertura das comportas do Açude Mãe D’Água (Figura 3), que se encontrava com 10,7\% de sua capacidade total (AESA 2016), realizada no dia 29 de setembro de 2016, perenizando, assim, o Rio Aguiar, tributário do Rio Piancó e abastecendo a população que era suprida com as águas do reservatório Curema.

Para que fosse possível a liberação da água do reservatório Mãe D’Água, foram necessárias intervenções nos barriletes do reservatório, que, segundo informações do Comitê, foram realizadas pela CAERN (Companhia de Águas e Esgotos do Rio Grande do Norte) junto com o DNCOS e outras entidades. Além disso, foi necessária a 
limpeza do leito do Rio Aguiar em todo seu percurso para um melhor escoamento das águas, esta, realizada por um termo de execução descentralizada entre a ANA e o DNOCS.

Figura 3. Perenização do Rio Aguiar por meio do Reservatório Mãe D’Água, Coremas-PB.

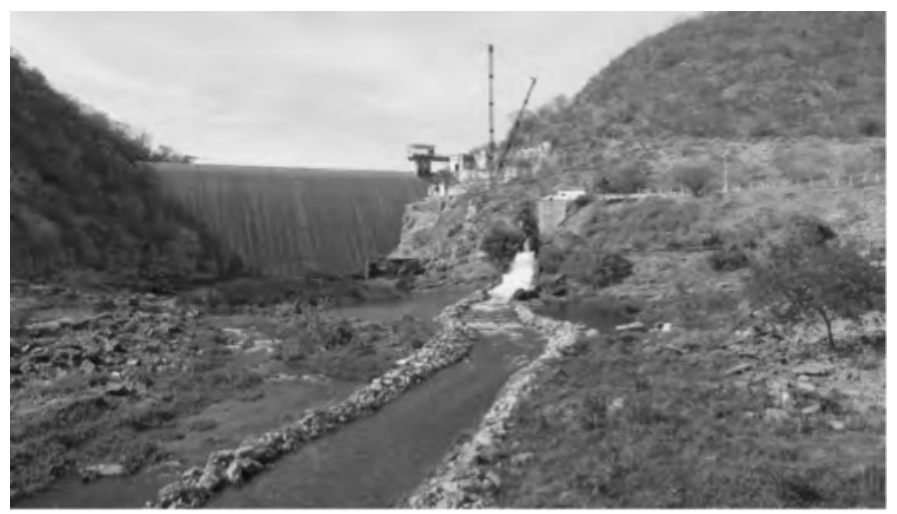

Fonte: Arquivo Pessoal de Juliana Fernandes Moreira, 2016

Essa ação revoltou a população da Comunidade Mãe D’Água que teve seu abastecimento por meio de barriletes suspensos, sendo impossibilitados de captarem água de forma direta do açude e que assistiam a mesma água ser fornecida para outros municípios da Paraíba e do Rio Grande do Norte. Além disso, segundo a líder comunitária, o interesse maior pelas águas era do estado vizinho, já que a obra teria sido realizada pela CAERN, com o principal objetivo de levar a água para grandes agricultores rurais, enquanto os moradores da comunidade estavam obrigados a utilizar uma quantidade limitada de água. Defendendo esse argumento a comunidade se organizou e realizou uma nova manifestação em 11 de novembro de 2016, contra as ações dos gestores hídricos.

Outra indignação manifesta pelos membros da Comunidade Mãe D’Água tem a ver com a liberação da água do açude Mãe D’Água para o abastecimento de outros municípios, lançando a água do açude no leito do Rio Aguiar, o que, segundo a população, gera perda significativa de água por evaporação, desvio no caminho do curso do rio, captação irregular e encharcamento do solo. Segundo a líder comunitária, é evidente o mau gerenciamento dos recursos hídricos. Além disso, segundo a mesma, a água deveria ser fornecida aos municípios por meio de adutoras, já que, qualquer perda, por menor que seja, torna-se relevante em momentos de crise hídrica.

E é importante destacar que a Paraíba, foi $100 \%$ fraca a respeito da briga pela sua água - pela sua água não, por que os mananciais quem gerencia é a ANA, mas a Paraíba era pra ter pegado um ponto e dizer: Não, não vai ser assim. Não vai ser assim. Esse trabalho aqui na Mãe D’Água quem fez, gente, foi a CAERN, quem fez foi a CAERN do Rio Grande do Norte... Quer dizer, a CAERN queria água, queria não, eles precisavam da água, eles também precisam de água para consumir. Mas era pra ter tido um meio termo. Não, vocês também precisam da água, mas vamos usar, ver como essa água vai pra aí. (M.A.S. 2017).

Segundo E.G, o Rio Grande do Norte, bem como outros municípios da Paraíba que, até então, eram abastecidas pelo açude Curema, estavam necessitando de água em virtude do colapso deste reservatório. O senhor E. afirma que o município de Coremas cruzou os braços para os problemas enfrentados pela Paraíba e pelo estado vizinho, não realizando as ações necessárias para a liberação da água do açude Mãe D’Água. Portanto, o que ocorreu, segundo o mesmo, foi uma parceria entre todos os órgãos gestores e, por necessidade e falta de atuação por parte do município supracitado, a CAERN se fez presente realizando a obra.

Ademais, P.A.O. também critica a forma de liberação de água em leito de rio em uma região que vive com os problemas causados pela estiagem, porém, não haveria tempo nem recursos financeiros para a construção de uma adutora para abastecimento da população. Além disso, segundo P.A.O., os interesses de uma comunidade de 600 
pessoas não devem prevalecer sobre o direito de abastecimento humano de outras 400 mil pessoas. Portanto, esta teria sido uma alternativa emergencial encontrada pelos órgãos gestores para levar água a quem precisava.

Por outro lado, a liberação de água em leito de rio tem aspectos importantes, já que a água infiltra no solo, servindo de sustento para a vegetação, além de possibilitar o reabastecimento de lençóis freáticos, em situações nos quais eles existam.

Além disso, segundo E.G., é impossível afirmar a existência de atividade de irrigação de grandes agricultores no Rio Grande do Norte, uma vez que, segundo ele, em meados de novembro de 2016, a água que estava sendo liberada pelo reservatório Mãe D’Água não estaria chegando em quantidade suficiente para tal atividade no estado supracitado, alcançando apenas o município de Jardim de Piranhas-RN (quase na divisa com o estado da Paraíba), sendo, até mesmo, necessária a criação de barramentos, por parte da população deste município para acumulação da água e captação da mesma.

Em fevereiro de 2017 precipitações de baixo volume caíram sobre a região da Bacia Hidrográfica do Rio Piranhas-Açu, despertando a esperança do povo sertanejo por chuvas de maiores proporções, na expectativa de que fossem capazes de gerar uma recarga considerável de água nos reservatórios da região. As chuvas se prolongaram nos meses subsequentes. Segundo dados da AESA, em fevereiro de 2017 os volumes dos reservatórios Curema e Mãe D'Água eram de $16.338 .069 \mathrm{~m}^{3}$ (2,8\% de sua capacidade total) e $24.552 .886 \mathrm{~m}^{3}$ (4,3\% de sua capacidade total) respectivamente e, em junho do mesmo ano, devido a ocorrência das referidas chuvas, os mesmos reservatórios atingiram o volume de 55.109.840 (9,3\% de sua capacidade total) e 31.750 .093 (5,6\% de sua capacidade total) respectivamente. Todavia, a população coremense, mesmo com a situação de colapso do reservatório Curema, continuava sendo abastecida por este através de bombas de captação. Vale ressaltar que a água que estava abastecendo a população estava com uma péssima qualidade, chegando às residências com um aspecto barrento, segundo relatos da comunidade coremense.

No dia 18 de abril de 2017 a ANA emitiu uma nota através da qual repassava a informação de que havia sido decidido de comum acordo com a AESA e o IGARN a retomada da perenização do Rio Piancó por meio das águas do reservatório Curema. Tal perenização, como dito anteriormente, fora suspensa em outubro de 2016 pelo fato deste encontrar-se em seu volume morto. Destarte, a descarga do açude Mãe D’Água, que teve início em outubro de 2016, foi interrompida, uma vez que o reservatório Curema retornou a um nível capaz de perenizar o leito do Rio Piancó, levando água para as regiões que dependem da mesma. A nota da ANA estabeleceu que a vazão a ser liberada pelo Curema seria de 5001/s, ou seja, o mesmo volume de água que estava sendo liberado pelo Mãe D’Água, bem como reforçou que a gestão das águas na região vem ocorrendo de forma articulada entre a PB e o RN e entre os órgãos gestores.

Todavia, em decorrência da nota emitida pela ANA, a população coremense, no dia 19 de abril de 2016, realizou uma grande mobilização, dirigindo-se até a estação de geração de energia elétrica da Companhia Hidrelétrica do São Francisco (Chesf), localizada no município de Coremas-PB, e invadindo o local, tendo por objetivo o fechamento da comporta do Curema, para evitar a liberação de água. Além disso, as vias de acesso ao município foram interditadas, uma vez que pneus foram colocados e neles ateado fogo. Diante dessa situação, foi convocada uma audiência pública, realizada no dia 22 de abril, na Câmara dos Vereadores, com a presença dos representantes dos gestores hídricos.

Durante a realização da audiência pública, que teve por objetivo discutir, junto com a população, a alocação de água que estava sendo efetuada pelo reservatório Curema, além de abrir espaço para os órgãos gestores explanarem os motivos da necessidade dessa deliberação, os coremenses manifestaram-se através de cartazes, uma vez que não lhes foi concedida a palavra durante a audiência. Os manifestantes encontravam-se insatisfeitos com a decisão tomada pela ANA, em 18 de abril de 2016, e estavam exigindo que a liberação de água do açude Curema fosse suspensa. Dentre as pessoas que se fizeram presente durante o evento, foi possível colher o relato de alguns coremenses que afirmaram ter tido o seu direito de acesso à água cerceado, conforme afirma G.T., moradora do centro da cidade de Coremas-PB. 
Um pouquinho que Jesus manda, ai vem nos manda chuva e tira, manda pra Pombal, São Bentinho, é... Paulista, Rio Grande do Norte. E nós aqui? Da terra? Nós, filho da terra vai morrer de sede? Não. Isso tá errado. Tá erradíssimo. Não tem água. Três dias que eu não vejo água na minha casa. Depois que a água... Que pegou água, não faltava!

Posteriormente, mais precisamente no dia 9 de maio de 2017, enquanto o reservatório Curema encontrava-se com apenas 8,2\% de sua capacidade total (AESA 2017), os órgãos responsáveis pela gestão das águas na bacia em análise estabeleceram a necessidade de aumento da vazão do reservatório para $2.000 \mathrm{l} / \mathrm{s}$, ou seja, o quádruplo do valor estabelecido no mês de abril, o que gerou mais um desconforto e indignação por parte da população local. Em junho do mesmo ano, o reservatório encontrava-se com 9,3\% de sua capacidade total, o que mostra uma evolução no volume de água armazenado na barragem, porém, insuficiente para despreocupar os gestores hídricos e os moradores da região em estudo.

\section{Conclusão}

A gestão dos recursos hídricos e o direito ao acesso à água são matérias que ganham destaque, especialmente em grandes períodos de estiagem nas regiões semiáridas. A gestão das águas revela-se, nessas ocasiões, como elemento impulsionador de mudanças na realidade cotidiana de Comunidades como foi demonstrado no caso de Mãe D’Água cuja sobrevivência está associada a atividades que dependem diretamente do uso da água.

Malgrado o novo modelo de gestão dos recursos hídricos adotado no país, adotado a partir de 1997, baseado no exemplo descentralizado francês, ter possibilitado a participação de vários atores sociais no processo de gestão dos recursos hídricos, inclusive atores sociais outrora excluídos como pequenas comunidades rurais e urbanas, a situação de escassez como a vivenciada nos últimos cinco anos no semiárido brasileiro, aumenta as chances da população não acatar certas decisões tomadas pelo conjunto de gestores, por se sentirem duplamente penalizadas: sem acesso à água e sem possibilidades de garantir a subsistência familiar através das atividades econômicas que desenvolvem.

A comunidade Mãe D’Água figura-se como um dos grupos afetados pela seca e pela gestão hídrica. A retirada dos barriletes do açude que abasteciam a comunidade por parte dos órgãos gestores embora se revele como uma ação necessária, e que tenha suporte na Política Nacional de Recursos Hídricos que prevê em períodos de escassez hídrica, a preferência de uso da água para a dessedentação animal e o abastecimento humano, retirou da população suas únicas fontes de renda submetendo-os à dependência de políticas públicas e da aposentadoria para viver.

Conclui-se, com base no exposto que em períodos longos de forte seca, os reservatórios como os de Curema e o de Mãe D’Água, ambos localizados na Bacia Hidrográfica do Rio Piranhas-Açu, mesmo com capacidade para significativa acumulação de água, são intensamente afetados promovendo problemas graves à população. A gestão participativa e descentralizada dos recursos hídricos mesmo quando agem de forma eficaz e eficiente não é capaz de evitar a eclosão de conflitos, uma vez que a escassez hídrica pode levar a uma crise hídrica, gerando insatisfação por parte dos consumidores desse recurso natural, a água, que vêm seu direito ao acesso à água sofrer limitação, como o que ocorreu com a população da Comunidade Mãe D’Água. Além disso, a ausência de equipamentos imprescindíveis para garantir uma situação minimamente sustentável para a população só é pensada quando os conflitos se aguçam como é o caso de instalação de adutoras.

Assim sendo, é possível que a implementação de infraestruturas básicas de suporte em períodos de chuvas normais e de formas alternativas de convivência com a seca através da implementação de tecnologias sociais diversas nas comunidades que dependem da água para desenvolver suas atividades econômicas, possa se constituir num fator de atenuação dos conflitos garantindo uma gestão hídrica mais eficiente e menos conflituosa nos momentos de escassez extrema. 


\section{REFERÊNCIAS}

AESA. Available from URL: http://site2.aesa.pb.gov.br/aesa/volumesAcudes.do.

AESA. Available from URL: http://www.aesa.pb.gov.br/comites/piranhasacu/.

Pompeu T. Águas doces no direito brasileiro. In: Pompeu, Tomanik. Águas doces no Brasil: capital ecológico, uso e conservação. São Paulo: Escrituras, 1999. p. 602.

Amorim AL. Mecanismos de Resolução de Conflitos em Bacias Hidrográficas Compartilhadas: o caso das Bacias dos rios Piranhas-Açu (Brasil) e Tejo (Península Ibérica). Tese de Doutorado. Campina Grande, Universidade Federal de Campina Grande (UFCG), 2016.

ANA. Plano de Recursos Hídricos da Bacia Hidrográfica do Rio Piranhas-Açu. Brasilia: Ministério do Meio Ambiente, 2014.

M.A.S. depoimento [nov. 2016]. Entrevistadores: O. Maria, L. Laryssa, M. Juliana, S. F. Valter. Paraíba: Coremas, 2016. Entrevista concedida ao Grupo de Pesquisa Direito de Acesso à Água em Tempos de Crise Hídrica do IDCC - Instituto de Pesquisa e Extensão Perspectivas e Novos Desafios de Humanização do Direito Civil - Constitucional.

Articulação Semiárido Brasileiro. Available from URL: http://www.asabrasil.org.br/acoes/p1-2>, <http://www.asabrasil. org.br/acoes/p1mc\#categoria_img.

Beviláqua C. Código Civil. 3 ed. São Paulo: Francisco Alves, 1927. v. 1.

Brasil. Constituição da República dos Estados Unidos do Brasil de 16 e Julho de 1934 Available from URL: <http:// www.planalto.gov.br/ccivil_03/constituicao/constituicao34.htm>.

Brasil. Constituição da República Federativa do Brasil de 1988. Available from URL: <http://www.planalto.gov.br/ ccivil_03/constituicao/constituicaocompilado.htm>.

Brasil. Decreto n 24.643 de 10 de Julho de 1934. Decreta o Código de Águas. Available from URL: <http://www.planalto. gov.br/ccivil_03/decreto/d24643.htm>.

Brasil. Decreto ${ }^{\mathbf{0}} \mathbf{6 . 0 4 0}$, de 7 de fevereiro de 2007. Available from URL: < http://www.planalto.gov.br/ccivil_03/_ato20072010/2007/decreto/d6040.htm>.

Brasil. Lei $\mathbf{n}^{\circ} \mathbf{9 . 4 3 3}$ de 8 de janeiro de 1997. Available from URL: <http://www.planalto.gov.br/ccivil_03/leis/L9433. htm>.

Brasil. Resolução no 407 de 11 de abril de 2016 da Agência Nacional de Águas (ANA). Available from URL: <http:// arquivos.ana.gov.br/resolucoes/2016/407-2016.pdf> .

Brito FB. O conflito pelo uso da água do açude Epitácio Pessoa (Boqueirão) -PB. Dissertação de mestrado. Programa de Pós-Graduação em Geografia - UFPB, 2006

Campos VNO, Fracalanza AP. Governança das águas no Brasil: conflitos pela apropriação da água e a busca da integração como consenso. Ambient. soc. [online]. 2010, vol.13, n.2, pp.365-382 
Cano W. Crise e industrialização no Brasil entre 1929 e 1954: a reconstrução do Estado Nacional e a política nacional de desenvolvimento. Rev. Econ. Polit. [online]. 2015, vol.35, n.3

Coelho AH. O bem ambiental, sua propriedade e os tribunais de contas. In Revista do Tribunal de Contas de Minas Gerais. ago/set/out/2012. P. 35-58. Available from URL: http://revista.tce.mg.gov.br/

C FN. Prefácio à Edição Portuguesa. In: Barraqué B. As águas na Europa. Trad. Fernanda Oliveira. Lisboa: Instituto Piaget, 1996, p. 12.

Fonseca JJS. Metodologia da pesquisa científica. Fortaleza, UEC, 2002

Fundação Cultural Palmares. Comunidades Remanescentes de Quilombos (CRQ’s). Available from URL: http://www. palmares.gov.br/?page_id=37551.

Granziera MLM. Direito de Águas. 4 ed. São Paulo: Atlas S.A., 2014.

IBGE. Atlas do Censo Demográfico 2010. Available from URL: http://www.censo2010.ibge.gov.br/sinopse/index. php?uf $=25 \&$ dados $=29$.

IBGE. Available from URL: http://cidades.ibge.gov.br/xtras/perfil.php?codmun=250400.

IBGE. Available from URL: http://cidades.ibge.gov.br/xtras/perfil.php?codmun=250480.

Lanna AE. Aspectos Conceituais da Gestão das Águas. Available from URL: https://www.passeidireto.com/ arquivo/1000547/lanna-cap1

Lederach JP. Transformação de Conflitos. 1 ed. São Paulo: Palas Athena, 2012.

Leite S. A gestão dos recursos hídricos no Brasil. Available from URL: http:/ /www.campomagro.pr.gov.br/wp-content/ uploads/2015/03/A-gest\%C3\%A3o-dos-recursos-h\%C3\%ADdricos-no-Brasil.pdf.

Lemos DS, Lemos, TRMS. Aspectos jurídicos da sustentabilidade da água. In: Âmbito Jurídico, Rio Grande, XII, n. 71, dez 2009. Available from URL: http://www.ambito-juridico.com.br/site/index.php?artigo_id=6994\&n_link=revista_artigos_ leitura.

Lima VRP. Conflito pelo Uso da Água do Canal da Redenção: Assentamento Acauã - Aparecida -PB. Dissertação de Mestrado: PPGE. João Pessoa: UFPB, 2006.

Mauro CAD. Conflitos pelo uso da água. In.: Caderno Prudentino de Geografia. Presidente Prudente, n. 36, volume especial, p. 81-105, 2014. Available from URL: http://revista.fct.unesp.br/index.php/cpg/article/view/3174/2679

Moreira JF. Legislação Ambiental e Conflitos Sócio-Ambientais: o caso da atividade carcinicultura na APA da Barra do Rio Mamanguape-PB. Dissertação (Mestrado) - UFPB/PRODEMA, 2008

Moreira ER, Targino I. Semiárido paraibano e a questão agrária: mudanças e perspectivas. Boletim Dataluta, v.105, 2016

Pinheiro MIT, Campos JNB, Sudart TMC. Conflitos por águas e alocação negociada: o caso do vale dos Carás no Ceará. In.: Rev. Adm. Pública [online]. 2011, vol. 45, n.6. Available from URL: http://www.scielo.br/scielo.php?script=sci_ arttext\&pid $=$ S0034-76122011000600003\&lng $=$ en\&nrm=iso . 
Pompeu CT. Direito de Águas no Brasil. 2a ed. São Paulo: Revista dos Tribunais, 2010. p. 315.

Sampaio LRC, Braga Neto A. O que é mediação de conflitos. São Paulo: Editora brasiliense, 2007

Santos JYG, Cunha TB, Vianna PCG. Conflito pelo uso da água no sertão paraibano: o estudo de caso do açude São Francisco II, Teixeira (PB). In.: Cadernos do Logepa, v. 6, n.2, p.140-160, jul/dez 2011. Available from URL: http://periodicos.ufpb. br/index.php/logepa/article/view/10873/6957

Secretaria de Estado da Mulher e da Diversidade Humana. Relatório I Seminário Estadual de Políticas Publica para Comunidades Quilombolas do Estado da Paraíba. Paraíba: 2011.

Simmel G. Conflito e estrutura de grupo. São Paulo: Ática, 1983

Tartuce F. Mediação nos conflitos civis. São Paulo: Ed. Método, 2008

Theodoro SH,. Uma crise anunciada. In Theodoro SH, et al. Mediação de Conflitos Socioambientais. Rio de Janeiro: Garamond, 2005.

G.T. Depoimento [abr. 2016]. Entrevistadores: M. Juliana, S. F. Valter. Paraíba: Coremas, 2017. Entrevista concedida ao Grupo de Pesquisa Direito de Acesso à Água em Tempos de Crise Hídrica do IDCC - Instituto de Pesquisa e Extensão Perspectivas e Novos Desafios de Humanização do Direito Civil - Constitucional. 